\title{
Is there a Gap or Congruency Effect? A Cross-Sectional Study in Students' Fraction Comparison
}

\author{
Juan Manuel González-Forte ${ }^{1}$, Ceneida Fernández ${ }^{1}$, Wim Van Dooren² \\ ${ }^{1}$ Departamento de Innovación y Formación Didáctica, Facultad de Educación, Universidad de Alicante, Calle Aeroplano, \\ s/n. 03690 San Vicente del Raspeig, Spain \\ ${ }^{2}$ Centre for Instructional Psychology and Technology, University of Leuven, Dekenstraat, 2, 3000 Leuven, Belgium
}

Many studies have addressed the natural number bias in fraction comparison, focusing on the role of congruency. However, the congruency effect has been observed to operate in the opposite direction, suggesting that a deeper explanation must underlie students' different reasoning. We extend previous research by examining students' reasoning and by studying the effect of a gap condition in students' answers. A cross-sectional study was conducted on 438 students from $5^{\text {th }}$ to $10^{\text {th }}$ grade. Results showed that the gap effect could explain differences between congruent and incongruent items. Moreover, students' use of gap thinking decreased towards the end of Secondary Education.

Key words: rational numbers, natural number bias, fraction comparison, gap thinking

\section{Introduction}

The rational number constitutes one of the most complex and important mathematical concepts that students have to learn. The concept underlies the understanding of a wide range of related concepts, including proportions, ratios and percentages, as well as more advanced concepts of algebra and calculus (Kieren, 1993). However, primary and secondary school students often have difficulties with different aspects of rational numbers, especially with fractions (Merenluoto \& Lehtinen, 2002).

Although different explanations have been put forward, research since the 1980s has found that students struggle with understanding different aspects of rational numbers because whole numbers knowledge interferes in their comprehension (Fischbein, Deri, Nello, \& Marino, 1985; Moss \& Case, 1999; Resnick et al., 1989). The concept of rational number is sometimes inconsistent with the properties of whole numbers (Fischbein et al., 1985). Kieren (1993) stated that "knowledge of the rational number is not a simple extension of the knowledge of the whole number" (p. 56). This tendency to regress to a property compatible with whole numbers was termed whole number dominance by Behr, Wachsmuth, Post, and Lesh (1984), while recent research has termed it whole/natural number bias (Ni \& Zhou, 2005; Van Dooren, Lehtinen, \& Verschaffel, 2015).

Correspondence concerning this article should be addressed to Juan Manuel González-Forte, Departamento de Innovación y Formación Didáctica, Facultad de Educación, Universidad de Alicante, Calle Aeroplano, s/n. 03690 San Vicente del Raspeig, Spain. E-mail: juanma.gonzalez@ua.es ORCID https://orcid.org/0000-0003-4020-7869

Received February 22, 2019 
The term bias describes the fact that knowledge of natural numbers can facilitate students' reasoning when activities of rational numbers are compatible with this knowledge, but it does not facilitate their reasoning when rational numbers behave differently from natural numbers (for a review, see Van Dooren et al., 2015).

Focusing on fractions, difficulties lie in "the tendency of students to treat fractions in the same way as natural numbers" (Streefland, 1991 , p. 70). For example, primary and secondary school students believe that a fraction's numerical value is represented by two independent natural numbers (Behr et al., 1984; Stafylidou \& Vosniadou, 2004) or that no other fractions can be found between two fractions such as $2 / 5$ and $3 / 5$ (Merenluoto \& Lehtinen, 2002). This tendency appears as soon as fractions are introduced and persists at least up to secondary school, decreasing with age but not altogether disappearing (Vamvakoussi, Van Dooren, \& Verschaffel, 2012).

Our study continues in this line of research. First, we discuss the theoretical and empirical background of the whole/natural number bias phenomenon, and particularly students' performances in fraction comparison items. We then highlight how our study extends this previous research.

\section{Theoretical and Empirical Background}

\section{The Natural Number Bias Phenomenon}

Research on natural number bias has focused on four dimensions in which rational numbers differ from natural numbers: density, representation, operations and size (Gómez \& Dartnell, 2019; McMullen, Laakkonen, HannulaSormunen, \& Lehtinen, 2015; Van Hoof et al., 2016; Vamvakoussi et al., 2012).

Density of rational numbers has been described as one of the most difficult concepts that primary and secondary school students have to address (McMullen et al., 2015; Vamvakoussi \& Vosniadou, 2004). Students seem to believe that there is no, or only a finite amount of numbers between any two rational numbers, as is the case with natural numbers (Smith, Solomon, \& Carey, 2005). For instance, primary school students think that there are no other numbers between 1.23 and 1.24 (Moss \& Case, 1999) or secondary school students think that between $1 / 2$ and $1 / 4$ there is only one, namely $1 / 3$ (Merenluoto \& Lehtinen, 2002).

With regard to representation, while natural numbers have only one symbolic representation, rational numbers can be represented in different ways. Many studies have shown that primary and secondary school students frequently fail to regard fractions and decimals as representations of the same number (Vamvakoussi et al., 2012). For instance, students have difficulties in considering $3 / 4,6 / 8$, 0.75 , and 0.750 to be the same number (Beyranevand, 2014).

Regarding arithmetic operations, primary and secondary school students' have shown difficulties especially in multiplications and divisions. Students believe that multiplications always result in a larger and divisions in a smaller number, which is not always the case for rational numbers (Vamvakoussi et al., 2012; Van Hoof et al., 2016). For example, $2 \times$ $2 / 3$ leads to a result smaller than 2 .

This latter aspect, size, is the focus of this paper. Regarding decimal representation, studies indicate that errors are frequently made in comparison tasks because contrary to natural numbers, the length (number of digits) of a decimal number does not always help to decide which is larger. In fact, primary school students think that "longer decimals are larger" and "shorter decimals are smaller" (Resnick et al., 1989). Difficulties also arise in comparing two fractions, as the counting sequence (order) which applies to natural numbers is no longer useful. In fact, because students have difficulties in understanding a fraction as a number, they tend to incorrectly assume that a fraction's numerical value increases with the increase of its denominator, numerator, or both together (DeWolf \& Vosniadou, 2015). For example, when comparing $4 / 4$ and $5 / 5$, primary and secondary school students consider $4 / 4$ smaller than $5 / 5$ because 4 is smaller than 5 . 
Since our study focuses on fraction comparison, a broader review of the literature addressing students' performances in these items is provided next.

\section{Students' Performances in Fraction Com- parison Items}

Previous studies have used fraction comparison items in which the largest fraction also has the largest numerator and denominator (e.g., $2 / 3$ vs. $7 / 8$ ) as well as fraction comparison items in which the largest fraction does not have the largest numerator and denominator (e.g., $2 / 3$ vs. 5/8). A reasoning consistent with natural number order leads to a correct answer in the first comparisons and, leads to an incorrect answer in the second (5/8 is larger than $2 / 3$ since 5 is larger than 2 , and 8 is larger than 3$)$.

In a study with $7^{\text {th }}$ and $11^{\text {th }}$ grade school students using fraction comparison items with one common component (numerator or denominator), Van Hoof, Lijnen, Verschaffel, and Van Dooren (2013) found more correct answers in items consistent with natural number knowledge than in items inconsistent with this knowledge. DeWolf and Vosniadou (2011) investigated the natural number bias in undergraduate students using fractions with no common components. Their results also showed that students were less accurate when the largest fraction in a comparison had the smallest numerator and denominator.

However, opposite results have also been found, mostly in studies using fractions with no common components. Students, in these cases, had more difficulties in fraction comparison items consistent with natural number knowledge. These results were found in studies with primary school students (Gómez \& Dartnell, 2019; Rinne, Ye, \& Jordan, 2017) and with university students (DeWolf \& Vosniadou, 2015; Gómez, Silva, \& Dartnell, 2017).

The findings above raise questions as to whether the effects obtained can be solely attributed to the natural number bias phenomenon, and whether other mechanisms may be at play at certain ages. Therefore, further re- search seems warranted. In this context, Gómez et al. (2017) showed that in mathematically-trained individuals, the natural number bias was not the best predictor of different performance in fraction comparison items consistent with natural number knowledge and in items inconsistent with this knowledge. In fact, data from their research with undergraduate Engineering students suggested that gap thinking was a viable way of thinking, which explained the differences in students' success in comparison items ascribed to the natural number bias.

Gap thinking (Pearn \& Stephens, 2004) is the belief that "the bigger the gap, the smaller the fraction", when students compare the difference (gap) between numerator and denominator. For example, $1 / 3$ is larger than $5 / 8$ because "from 1 to 3 there is a gap of two and from 5 to 8 there is a gap of three" (Moss \& Case, 1999; Pearn \& Stephens, 2004). This incorrect way of thinking has been considered a case of natural number dominance, since students overlook the multiplicative relationship between numerator and denominator (Clarke \& Roche, 2009). However, in the present study, we consider that gap thinking constitutes a separate phenomenon from natural number biased thinking described above, since there are differences between both reasonings. The first considers the relation between the two components of the fraction (it focuses on the difference between numerator and denominator rather than the ratio) while the second centers on the size of the components separately.

In some fraction comparison items, a different gap exists between numerator and denominator in which gap thinking leads to a correct answer such as the pair of fractions $2 / 7$ and $5 / 8$ (5/8 is larger than $2 / 7$ and there is a gap of five between 2 and 7 and a gap of three between 5 and 8). In other items, a different gap between numerator and denominator exists, in which gap thinking leads to an incorrect answer, such as the pair of fractions $7 / 9$ and $2 / 3(7 / 9$ is larger than $2 / 3$ and there is a gap of two between 7 and 9 and a gap of one between 2 and 3 ). Finally, in certain items with 
the same gap, gap thinking leads to an incorrect answer, because students can think that the two fractions (e.g., 2/3 and 4/5) are equal "since the difference between numerator and denominator is the same" (Clarke \& Roche, 2009; Moss \& Case, 1999).

\section{The Present Study}

We focused on how Spanish primary and secondary school students solve and justify fraction comparison items in order to explore students' reasoning in these items. Two conditions were taken into account in the following items: items where using natural number knowledge as described above leads students to the correct answer (congruent items) and items where using natural number knowledge leads to the incorrect answer (incongruent items) (in this study congruency condition); items with a different gap between the numerator and denominator (where, in this case, relying on the gap leads students to the correct answer) and items with the same gap (where relying on gap thinking leads students to incorrectly believing the fractions are equally large) (in this study gap condition).

As we have shown in the literature review, many studies have investigated the natural number bias in the domain of size and, particularly, in fraction comparison. However, we extend previous research in three ways. Firstly, research has been based only - to the best of our knowledge - on multiple-choice questionnaires (DeWolf \& Vosniadou, 2011; Gómez \& Dartnell, 2019) with a focus on answer correctness, and possibly reaction time. These studies did not examine students' underlying reasoning but rather deduced it from performance and/or reaction time. Qualitative data on students' reasoning could support previous hypotheses. Secondly, as far as we know, apart from the longitudinal studies of Van Hoof, Degrande, Ceulemans, Verschaffel, and Van Dooren (2018) and McMullen et al. (2015), no cross-sectional studies have shown the development from primary education (where fractions are introduced) to secondary education, allowing to investigate the grades in which natural number bias or the use of gap thinking is greater and whether they disappear at the end of secondary education. Finally, we extend previous research by adding the gap condition. This condition allows us to study whether the results obtained in other studies showing better performance in items inconsistent with natural number knowledge could be explained by the fact that students use gap thinking.

Our study had two objectives. First, we sought to test hypotheses raised in previous quantitative studies by analyzing students' reasoning. We expected items consistent with natural number knowledge to have higher accuracies than items inconsistent with this knowledge (Van Hoof et al., 2013). We also expected this effect to decrease with age, while also persisting until the last years of secondary education (DeWolf \& Vosniadou, 2011). Second, we wished to study the effect of gap condition and in interaction with the congruency condition. It could be possible that as the role of congruency diminishes with age, gap starts to influence students' reasoning.

\section{Method}

\section{Participants}

The participants were 438 primary and secondary school students: 85 fifth graders (1011 year olds), 81 sixth graders (11-12 year olds) from two different Spanish primary schools and 78 seventh graders (12-13 year olds), 81 eighth graders (13-14 year olds), 57 ninth graders (14-15 year olds), and 56 tenth graders (15-16 year olds) from two different Spanish secondary schools. There was approximately the same number of boys and girls in each age group. The participating schools were located in different cities and students were from mixed socio-economic backgrounds.

\section{Instrument and Procedure}

The instrument was a test consisting of four fraction comparison items (Table 1). These items were designed taking into account the congruency and gap conditions. In each item, students 
Table 1 Characteristics of the items

\begin{tabular}{cccc}
\hline & Pair of fractions & $\begin{array}{c}\text { Congruent/Incongruent } \\
(\mathrm{C} / \mathrm{I})\end{array}$ & $\begin{array}{c}\text { Same/Different gap } \\
(\mathrm{S} / \mathrm{D})\end{array}$ \\
\hline Item 1 & $2 / 3$ vs. $7 / 8$ & $\mathrm{C}$ & $\mathrm{S}$ \\
Item 2 & $2 / 7$ vs. $5 / 8$ & $\mathrm{C}$ & $\mathrm{D}$ \\
Item 3 & $5 / 3$ vs. $9 / 7$ & $\mathrm{I}$ & $\mathrm{S}$ \\
Item 4 & $2 / 3$ vs. $5 / 8$ & $\mathrm{I}$ & $\mathrm{D}$ \\
\hline
\end{tabular}

had to circle the largest fraction and explain why they thought that the fraction they chose was the largest. Furthermore, the following note was included in the test: "if you think both fractions are equally large, circle both".

The first two items required comparing two pairs of fractions consistent with the order of natural numbers (congruent items). The largest fraction had a numerator and denominator larger than the smallest fraction (2/3 vs. $7 / 8$ and $2 / 7$ vs. $5 / 8$ ). But in the first pair of fractions ( $2 / 3$ vs. $7 / 8)$, the gap between the numerator and denominator was the same (the gap between 2 and 3 is 1 , and between 7 and 8 is 1), while in the second pair of fractions (2/7 vs. $5 / 8$ ), the gap was different (the gap between 2 and 7 is 5 and between 5 and 8 is 3 ). In this last pair of fractions, gap thinking leads to a correct answer since the gap between 5 and 8 is 3 , the gap between 2 and 7 is 5 and $5 / 8$ is larger than $2 / 7$.

The other two items required comparing two pairs of fractions that were inconsistent with the order of natural numbers (incongruent items). The largest fraction had a smaller numerator and denominator than the smallest fraction ( $5 / 3$ vs. $9 / 7$ and $2 / 3$ vs. $5 / 8)$. In the first pair of fractions $(5 / 3$ vs. $9 / 7)$, the gap between the numerator and denominator was the same (the gap between 5 and 3 is 2 , and between 9 and 7 is 2). Despite the fact that both were improper fractions (and therefore may be more complex than proper ones), we had to use them to fulfil the condition of incongruent items with the same gap. Creating such items with proper fractions is mathematically impossible. We believed that the use of improper fractions would not affect students whose reasoning was based on the order of natural numbers, since they only consider the size of numerator and denominator independently. Furthermore, they would not affect students who use gap thinking either, since they consider the difference (additively) between numerator and denominator. In the second pair of fractions $(2 / 3$ vs. $5 / 8$ ), the gap was different (the gap between 2 and 3 is 1 and between 5 and 8 is 3 ). In this comparison, gap thinking leads to a correct answer since the gap between 2 and 3 is 1 , the gap between 5 and 8 is 3 and $2 / 3$ is larger than $5 / 8$. Table 1 summarizes the characteristics of each item.

Therefore, students whose reasoning was based on natural number knowledge would answer congruent items ( 1 and 2) correctly and incongruent items (3 and 4) incorrectly. Students whose reasoning is based on gap thinking would answer items 2 and 4 correctly and items 1 and 3 incorrectly.

Students could use all the time they needed to solve all items, because we were interested in examining their reasoning. The test took approximately 10 to 15 minutes. There were no further test instructions except that of forbidding students to use calculators or mobile devices.

\section{Analysis}

The analysis was conducted in two phases. In the first phase, students' success levels were examined in each item and grade. In the second phase, we examined the type of reasoning used, based on their written justifications.

Answers were first classified as correct if the largest fraction was encircled, and as incorrect otherwise. Correctness was analyzed by means of a repeated measures logistic regression analysis, using generalized estimating of equations (GEE). 
Second, the type of reasoning was coded. We carried out an inductive analysis to generate categories. First, a subset of students' answers was independently analyzed by three researchers. We then compared our results and discussed our discrepancies until reaching an agreement. Subsequently, new data samples were added in order to revise our categories. Finally, four categories of correct reasoning and three categories of incorrect reasoning emerged. Since we were interested in this particular study in students' incorrect reasoning based on knowledge of natural numbers or gap thinking, we only describe here these latter two emerging categories.

- Based on the order of natural numbers. In this reasoning, the largest fraction is the fraction whose numerator and denominator are bigger. Figure 1 shows an example of the use of this incorrect reasoning in an incongruent item.

- Based on gap thinking. In this reasoning, the largest fraction is the fraction in which the difference between the numerator and denomi-

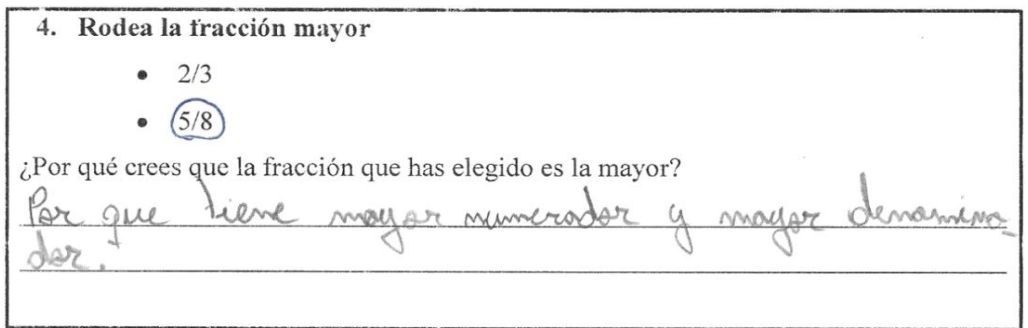

Figure 1 "Because the numerator and denominator of this fraction are bigger" ( $7^{\text {th }}$ grade student)

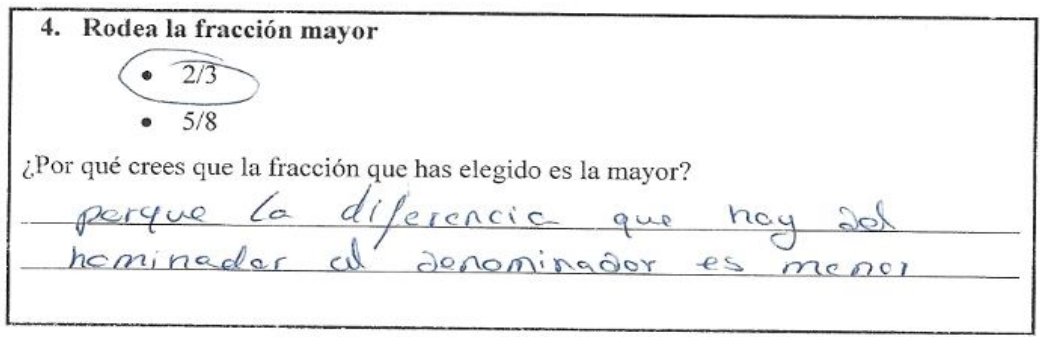

Figure 2 "Because the difference between the numerator and the denominator is smaller" $\left(10^{\text {th }}\right.$ grade student)

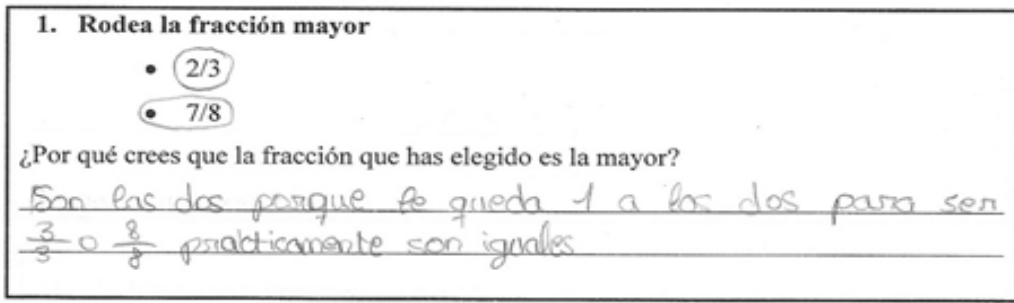

Figure 3 "Because both fractions need one to complete the $3 / 3$ or $8 / 8^{\text {" ( }} 5^{\text {th }}$ grade student) 
nator is the smallest in items with a different gap (Figure 2), or in which both fractions are equal since the gap is the same, in items with the same gap (Figure 3 ).

\section{Results}

This results section is divided into three subsections. First, we describe the results of the main effect of congruency and gap as well as the interaction effect. Second, we discuss changes with age. Third, we look at students' reasoning to provide further explanations of the quantitative analysis.

\section{Effects of Congruency and Gap on Students' Answers}

Students were much more successful in congruent items $(82.56 \%)$ than in incongruent ones $(50.16 \%)$. A repeated measures logistic regression analysis showed that this difference was significant, $X^{2}(1, N=438)=182.51$, $p<0.001$. Furthermore, students were significantly more successful in comparisons with a different gap than with the same gap $(71.06 \%$ vs. $61.67 \%), X^{2}(1, N=438)=30.93, p<0.001$.

There was also a significant 'gap' $\times$ 'congruency' interaction effect, $X^{2}(5, N=438)=4.11$, $p<0.043$. Pairwise comparisons (Figure 4) showed that in both congruent and incongruent items, students were significantly more successful in the item with a different gap than in the item with the same gap $(88.70 \%$ vs. $76.41 \%$ in congruent items, $p<0.001$ and $53.71 \%$ vs. $46.91 \%$ in incongruent items, $p=$ $0.006)$. However, that gap effect was bigger in congruent items (odds ratio $=2.42$ ) than in incongruent ones (odds ratio $=1.31$ ).

\section{Changes with Age}

Figure 5 shows the percentages of correct answers per grade. There was a decrease from $5^{\text {th }}$ to $8^{\text {th }}$ grade in congruent items (in both, with the same and different gap) and then, an increase from $8^{\text {th }}$ to $10^{\text {th }}$ grade. However, differences between grades were not significant. Regarding incongruent items, there was an increase in the number of correct answers from $5^{\text {th }}$ to $9^{\text {th }}$ grade (in both, with the same and different gap) and then a decrease from $9^{\text {th }}$ to $10^{\text {th }}$ grade. Differences were significant between $5^{\text {th }}$ and $6^{\text {th }}$ grade $(p=0.01)$ and between $8^{\text {th }}$ and $9^{\text {th }}$ grade $(p=0.002)$.

There was a significant 'grade' $\times$ 'congruency' interaction effect, $X^{2}(5, N=438)=53.00$, $p<0.001$, revealing that students were more successful in congruent items than in incongruent items in each grade. There were sig-

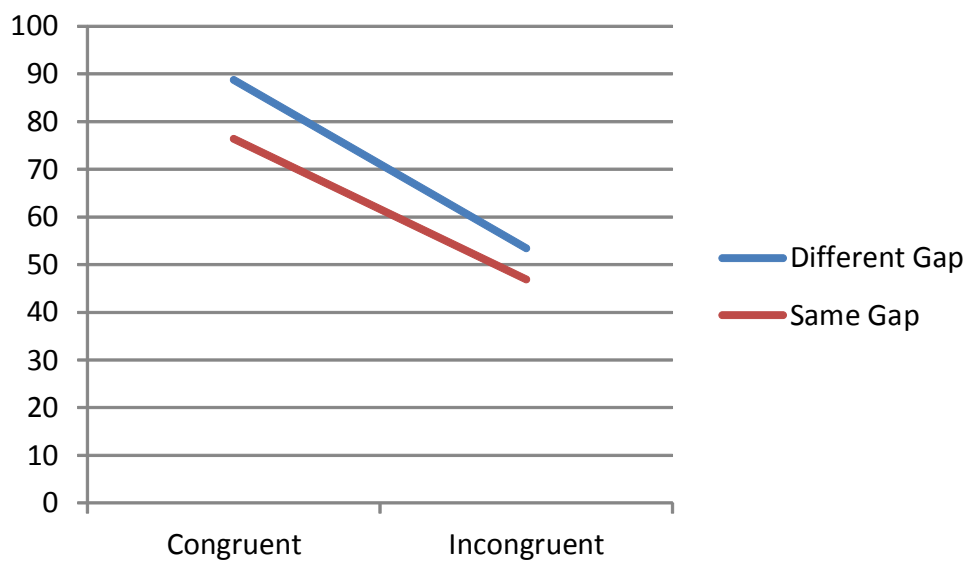

Figure 4 Interaction between congruency and gap 
nificant differences in all grades except $9^{\text {th }}$ grade $\left(p<0.001\right.$ in $5^{\text {th }}$ grade; $p<0.001$ in $6^{\text {th }}$ grade; $p<0.001$ in $7^{\text {th }}$ grade; $p=0.001$ in $8^{\text {th }}$ grade; $p<0.001$ in $10^{\text {th }}$ grade) (Table 2). Although differences between congruent and incongruent items were significant from $5^{\text {th }}$ to $8^{\text {th }}$ grade, these differences became smaller with age. In fact, differences in $8^{\text {th }}$ and $9^{\text {th }}$ grade between congruent and incongruent items were the smallest.

There was no significant interaction effect of the variables 'grade' $\times$ 'gap', $X^{2}(5, N=438)=$ $1.86, p<0.868$. However, differences between items with a different and same gap were significant in all grades except $10^{\text {th }}$ grade $(p<$ 0.001 in $5^{\text {th }}$ grade; $p=0.029$ in $6^{\text {th }}$ grade; $p=$ 0.046 in $7^{\text {th }}$ grade; $p=0.006$ in $8^{\text {th }}$ grade; $p=$ 0.017 in $^{\text {th }}$ grade) (Table 3 ). Table 3 also reveals that although differences between items with a different and same gap were significant, the differences were greatest in $8^{\text {th }}$ grade. In fact, $8^{\text {th }}$ grade students obtained the lowest percentages of accuracy in items with the same gap $(54.32 \%)$, where gap thinking leads to an incorrect answer. On the other hand, $9^{\text {th }}$ grade students obtained the highest percent-

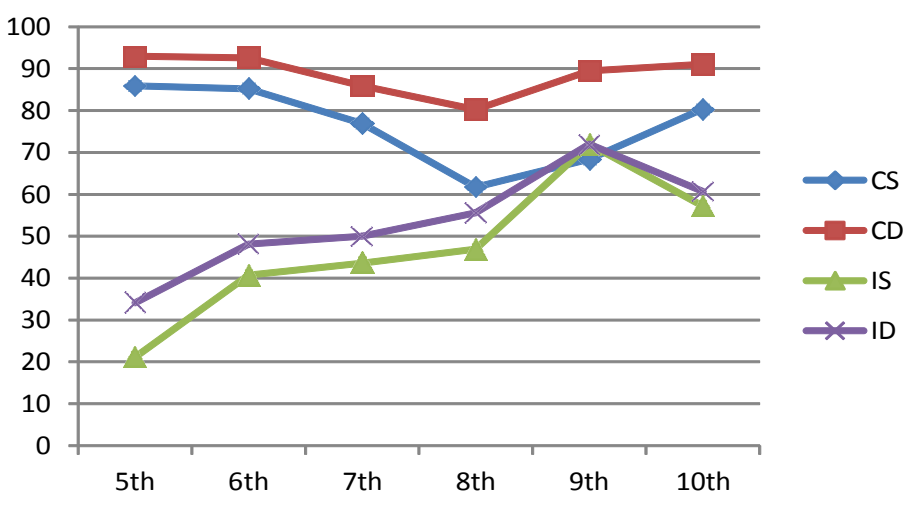

Note. CS: Congruent with the same gap; CD: Congruent with different gap; IS: Incongruent with the same gap; ID: Incongruent with different gap

Figure 5 Percentages of correct answers from $5^{\text {th }}$ to $10^{\text {th }}$ grade

Table 2 Percentages of students' correct answers in congruent and incongruent items

\begin{tabular}{ccc}
\hline Grade & Congruent & Incongruent \\
\hline $5^{\text {th }}$ & 89.41 & 27.65 \\
$6^{\text {th }}$ & 88.89 & 44.44 \\
$7^{\text {th }}$ & 81.41 & 46.79 \\
$8^{\text {th }}$ & 70.99 & 51.23 \\
$9^{\text {th }}$ & 78.95 & 71.93 \\
$10^{\text {th }}$ & 85.71 & 58.93 \\
\hline
\end{tabular}


ages of accuracy in items with a different gap $(80.70 \%)$, where gap thinking leads to the correct answer.

Finally, there was a nearly significant interaction effect of the variables 'grade' $x$ 'congruency' $\times$ 'gap', $X^{2}(5, N=438)=10.65, p<$ 0.059 . Figure 5 and Table 4 show that a greater gap effect existed in the congruent items than in the incongruent items from $6^{\text {th }}$ to $9^{\text {th }}$ grade. Differences were significant for congruent items in $5^{\text {th }}$ grade $(p=0.029)$ $(85.88 \%$ in same gap and $92.94 \%$ in different gap), $7^{\text {th }}$ grade $(p=0.016)(76.92 \%$ vs. $85.90 \%), 8^{\text {th }}$ grade $(p=0.002)(61.73 \%$ vs. $80.25 \%)$, and in $9^{\text {th }}$ grade $(p<0.001)(68.42 \%$ vs. $89.47 \%$ ). They were not significant for incongruent items in these grades, except in $5^{\text {th }}$ grade $(p<0.005)(21.18 \%$ in same gap and $34.12 \%$ in different gap).

\section{Students' Reasoning}

Figure 6 shows the percentages of the students' use of reasoning based on the order of natural numbers (NN) and the use of reasoning based on gap thinking (GT) out of the total number of given justifications from $5^{\text {th }}$ to $10^{\text {th }}$ grade. The remaining percentage in each item corresponds to other correct and incorrect students' reasoning.

In the four items, natural number bias reasoning (NN) decreased, but at the same time also predominated, from $5^{\text {th }}$ to $8^{\text {th }}$ grade. In $8^{\text {th }}$ grade, natural number bias reasoning and reasoning based on gap thinking was used approximately to the same degree. In $9^{\text {th }}$ grade, natural number bias increased again in the items with the same gap (where gap thinking does not lead to

Table 3 Percentages of students' correct answers in items with a different and same gap

\begin{tabular}{ccc}
\hline Grade & Same & Different \\
\hline $5^{\text {th }}$ & 53.53 & 63.53 \\
$6^{\text {th }}$ & 62.96 & 70.37 \\
$7^{\text {th }}$ & 60.26 & 67.95 \\
$8^{\text {th }}$ & 54.32 & 67.90 \\
$9^{\text {th }}$ & 70.18 & 80.70 \\
$10^{\text {th }}$ & 68.75 & 75.89 \\
\hline
\end{tabular}

Table 4 Percentages of students' correct answers in congruent and incongruent items with a same and different gap along grades

\begin{tabular}{ccccc}
\hline & \multicolumn{2}{c}{ Congruent } & \multicolumn{2}{c}{ Incongruent } \\
\hline Grade & Same & Different & Same & Different \\
\hline $5^{\text {th }}$ & 85.88 & 92.94 & 21.18 & 34.12 \\
$6^{\text {th }}$ & 85.19 & 92.59 & 40.74 & 48.15 \\
$7^{\text {th }}$ & 76.92 & 85.90 & 43.59 & 50.00 \\
$8^{\text {th }}$ & 61.73 & 80.25 & 46.91 & 55.56 \\
$9^{\text {th }}$ & 68.42 & 89.47 & 71.93 & 71.93 \\
$10^{\text {th }}$ & 80.36 & 91.07 & 57.14 & 60.71 \\
\hline
\end{tabular}


CS

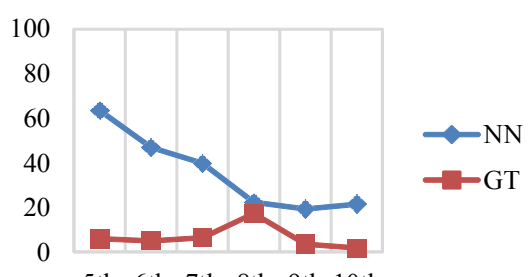

5th 6 th 7 th 8 th 9 th 10 th

IS

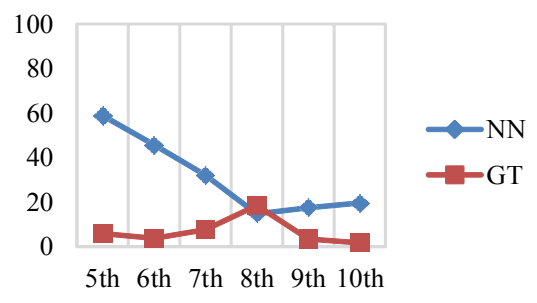

CD

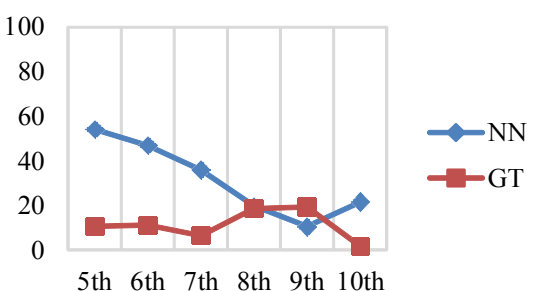

ID

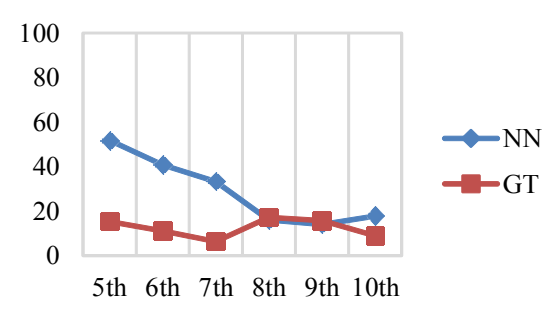

Note. CS: Congruent with the same gap; CD: Congruent with a different gap; IS: Incongruent with the same gap; ID: Incongruent with a different gap

Figure 6 Students' use of reasoning based on the order of natural numbers (NN) and the use of reasoning based on gap thinking (GT)

the correct answer) and in items where the gap is different, the use of gap thinking exceeded the use of natural number bias, though its use decreased in $10^{\text {th }}$ grade.

Overall, we can conclude that reasoning based on the order of natural numbers (NN) decreased with age but had not disappeared by the end of secondary school (10th grade): over $20 \%$ of the students used this reasoning in congruent items (leading students to produce correct answers) and in incongruent ones (leading them to produce incorrect answers). The drop in the use of this reasoning coincided with an increase of correct answers in incongruent items from 5 th to 9 th grade and a decrease of correct answers in congruent items from 5th to 8th grade (Figure 5).

Regarding gap thinking (GT) reasoning, there was a notable appearance of this type of reasoning in $8^{\text {th }}$ grade $(17.28 \%$ in CS, $18.52 \%$ in CD, $18.52 \%$ in IS, and $17.28 \%$ in ID) while it was much less present before this grade. In $9^{\text {th }}$ grade, this reasoning only appeared in items with a different gap $(19.30 \%$ in CD and $15.79 \%$ in ID), where gap thinking leads to the correct answer. The increase of the use of this reasoning with regard to the natural number bias could explain why differences in students' success levels between congruent and incongruent items were smaller in $8^{\text {th }}$ and $9^{\text {th }}$ grade (Table 2). Therefore, gap thinking influenced differences between students' success levels in congruent and incongruent items in $8^{\text {th }}$ and $9^{\text {th }}$ grade. This reasoning allows students to achieve a correct answer in items with a different gap but leads students to an incorrect answer in items with the same gap. However, the use 
of gap thinking reasoning dropped considerably from $8^{\text {th }}$ to $10^{\text {th }}$ grade.

\section{Discussion and Conclusions}

We conducted a cross-sectional study on $5^{\text {th }}$ to $10^{\text {th }}$ grade students examining their answers and reasoning in fraction comparison items, pursing two objectives. The first objective was to verify hypotheses inferred from previous quantitative studies by analyzing students' reasoning (congruency effect); the second objective was that of studying the effect of gap as a main condition and in interaction with congruency. We searched for evidence both in terms of accuracy and in students' written justifications. Generally, our results showed that both primary and secondary school students have difficulties with fraction comparison items, the natural number bias (Ni \& Zhou, 2005; Vamvakoussi et al., 2012; Van Dooren et al., 2015) being the main reason students fail in fraction comparison.

As in previous studies, better performance was observed in congruent comparison items than in incongruent comparison items (DeWolf \& Vosniadou, 2011). The qualitative analysis of students' reasoning supported the fact that in many cases, students think that a fraction is larger if the numerator and denominator are bigger (Behr et al., 1984; DeWolf \& Vosniadou, 2011; Moss \& Case, 1999). This reasoning is based on the knowledge of natural numbers, since students consider the numerator and denominator as two independent numbers (Behr et al., 1984; Stafylidou \& Vosniadou, 2004) and apply natural number ordering knowledge to compare fractions. Therefore, our results support the hypotheses inferred from previous studies in relation to congruency effects. Our data collection method, however, was different since we used four fraction comparison items and asked students to describe their reasoning, instead of using a large number of items in multiple-choice questionnaires.

Interestingly, although students were significantly more successful in congruent items than in incongruent items in each grade, differences between congruent and incongruent items became smaller with age. In fact, differences in $8^{\text {th }}$ and $9^{\text {th }}$ grade between congruent and incongruent items were the smallest. This result is discussed later in interaction with the gap effect. Furthermore, the number of students' correct answers decreased in congruent items from $5^{\text {th }}$ to $8^{\text {th }}$ grade and then increased from $8^{\text {th }}$ to $10^{\text {th }}$ grade. Our qualitative analysis showed that this was explained by a drop in the frequency of student reasoning based on knowledge of natural numbers compatible with these items. At the same time, there was an increase in the number of correct student answers from $5^{\text {th }}$ to $9^{\text {th }}$ grade, which also came with a decrease in reasoning based on natural numbers, which is incompatible with these items. However, although the use of the reasoning based on the order of natural numbers decreases with age, it does not entirely disappear by the end of secondary school education ( $10^{\text {th }}$ grade), since over $20 \%$ of the students used this reasoning in each item.

Furthermore, fraction comparisons with a different gap obtained better results than fraction comparisons with the same gap, and this effect was greater in congruent items than in incongruent items. Therefore, the gap condition influenced students' responses since gap thinking (Pearn \& Stephens, 2004) leads to a correct answer in comparisons with a different gap, while it suggests that both fractions are the same in items with the same gap. This result was also supported by the qualitative analysis of students' reasoning where students reason that a fraction is larger when the gap between numerator and denominator is smaller. Gap thinking could be a suitable way of thinking when students notice that there is an identical gap in terms of absolute number but the size of each gap is smaller. For instance, $5 / 6$ and $7 / 8$ have a gap of one, but the second fraction has eighths as a gap, therefore the one missing in the second fraction makes the second fraction larger. However, students considered the absolute difference, and gap thinking thus led to an incorrect answer. That condition affected primary and sec- 
ondary school students' responses in our study, in accordance with the study of Gómez et al. (2017), which found that gap-related conditions significantly affected participants' responses (undergraduate students of Engineering).

Differences between items with a different and same gap were significant from $5^{\text {th }}$ to $9^{\text {th }}$ grade but not in $10^{\text {th }}$ grade. However, the biggest difference was found in $8^{\text {th }}$ grade. In fact, $8^{\text {th }}$ grade students obtained the lowest percentages of accuracy in items with the same gap, which are items where gap thinking leads to the incorrect answer. Furthermore, the use of a reasoning based on gap thinking decreased at the end of secondary school.

Interestingly, in relation to differences in students' correct answers in $8^{\text {th }}$ and $9^{\text {th }}$ grade between congruent and incongruent items, differences in these grades were smaller and not significant. Our qualitative analysis provided an explanation: although there is a decrease of the reasoning based on the order of natural numbers in these grades, there was a noticeable increase in the use of gap thinking in $8^{\text {th }}$ grade in all items, persisting in $9^{\text {th }}$ grade in items with a different gap. Therefore, the gap condition influences differences between congruent and incongruent items in $8^{\text {th }}$ and $9^{\text {th }}$ grade. As Gómez et al. (2017) showed with mathematically-trained individuals, our data supports the claim that the gap effect could explain differences between congruent and incongruent items, extending this result from primary to secondary school. However, it seems that this effect decreases (in Spanish students) at the end of Secondary Education.

This result seems to indicate that as Spanish secondary school students start to leave behind their reasoning based on properties of natural numbers when working with rational numbers, they do not necessarily replace this type of reasoning by the correct kind of reasoning. Some of them begin to use a reasoning based on gap thinking instead of a correct reasoning. The difference between the use of a reasoning based on the natural number properties or a reasoning based on gap thinking is that, in the former, students regard the numera- tor and denominator as independent from one another, and in the latter, students believe there is an additive relationship, rather than a multiplicative one, between numerator and denominator. It could be argued that this is already a step forward in the development of rational number understanding, as a rational number is already conceived as a relation between two natural numbers. But a further step needs to be taken to understand that relation in a multiplicative way. This finding is not only theoretically important; it may also have practical implications. Teachers attending students, who reason about fractions in terms of natural number knowledge should be aware that these students may not necessarily develop a correct understanding once natural numberbased understanding is addressed. New, qualitatively different misunderstandings may start to occur.

We believe our study has produced important conclusions, such as the influence of gap and the interaction effect between congruency and gap that explains non-significant differences between congruent and incongruent items in certain grades. There are, however, some limitations to our study. Firstly, future studies should include more items in order to obtain further information about the interaction between congruency and gap conditions, including items with a different gap where gap thinking leads to an incorrect answer. Because we focused on students' reasoning, our study, however, included four items only; with more items, students would be reluctant to verbalize their reasoning. Secondly, the qualitative data was self-reported. Students may have verbalized their reasoning differently from what they actually thought. Therefore, further research is needed in this line, for example, conducting interviews where students have to solve fraction comparison items in real time.

\section{Acknowledgements}

This research was carried out with the support of Conselleria d'Educació, Investigació, Cultura i Esport (Generalitat Valenciana Spain) (PROMETEO/2017/135) and with the 
support of University of Alicante (UAFPU2018035).

\section{References}

Behr, M. J., Wachsmuth, I., Post, T. R., \& Lesh, R. (1984). Order and equivalence: A clinical teaching experiment. Journal of Research in Mathematics Education, 15(5), 323-341. https://doi.org/ $10.2307 / 748423$

Beyranevand, M. L. (2014). The different representations of rational numbers. Mathematics Teaching in the Middle School, 19(6), 382-385.

Clarke, D. M., \& Roche, A. (2009). Students' fraction comparison strategies as a window into robust understanding and possible pointers for instruction. Educational Studies in Mathematics, 72(1), 127-138. https://doi.org/10.1007/ s10649-009-9198-9

DeWolf, M., \& Vosniadou, S. (2011). The whole number bias in fraction magnitude comparisons with adults. In L. Carlson, C. Hoelscher, \& T. F. Shipley (Eds.), Proceedings of the 33rd Annual Conference of the Cognitive Science Society (pp. 17511756). Austin, TX: Cognitive Science Society.

DeWolf, M., \& Vosniadou, S. (2015). The representation of fraction magnitudes and the whole number bias reconsidered. Learning and Instruction, 37, 39-49. https://doi.org/10.1016/ j.learninstruc.2014.07.002

Fischbein, E., Deri, M., Nello, M. S., \& Marino, M. S. (1985). The role of implicit models in solving verbal problems in multiplication and division. Journal for Research in Mathematics Education, 16, 3-17. https://doi.org/10.2307/748969

Gómez, D., \& Dartnell, P. (2019). Middle schoolers' biases and strategies in a fraction comparison task. International Journal of Science and Mathematics Education, 17(6), 1233-1250. https:// doi.org/10.1007/s10763-018-9913-z

Gómez, D. M., Silva, E., \& Dartnell, P. (2017). Mind the gap: Congruency and gap effects in engineering students' fraction comparison. In B. Kaur, W. K. Ho, T. L. Toh, \& B. H. Choy (Eds.), Proceedings of the $41^{\text {st }}$ Conference of the International Group for the Psychology of Mathematics Education (vol. 2, pp. 353-360). Singapore: PME.

Kieren, T. E. (1993). Rational and fractional numbers: From quotient fields to recursive understanding. In T. P. Carpenter, E. Fennema, \& T. A. Romberg (Eds.), Rational numbers: An integration of research (pp. 49-84). Hillsdale, NJ: Lawrence Erlbaum Associates, Inc.

McMullen, J., Laakkonen, E., Hannula-Sormunen, M., \& Lehtinen, E. (2015). Modeling the developmental trajectories of rational number concept(s). Learning and Instruction, 37, 14-20. https://doi.org/ 10.1016/j.learninstruc.2013.12.004

Merenluoto, K., \& Lehtinen, E. (2002). Conceptual change in mathematics: Understanding the real numbers. In M. Limon, \& L. Mason (Eds.), Reconsidering conceptual change: Issues in theory and practice (pp. 233-258). Dordrecht: Kluwer Academic Publishers.

Moss, J., \& Case, R. (1999). Developing children's understanding of the rational numbers: A new model and an experimental curriculum. Journal for Research in Mathematics Education, 30, 122147. https://doi.org/10.2307/749607

Ni, Y., \& Zhou, Y. D. (2005). Teaching and learning fraction and rational numbers: The origins and implications of whole number bias. Educational Psychologist, 40(1), 27-52. https://doi.org/10.1207/ s15326985ep4001_3

Pearn, C., \& Stephens, M. (2004). Why you have to probe to discover what year 8 students really think about fractions. In I. Putt, R. Faragher, \& M. McLean (Eds.), Mathematics education for the third millennium: Towards 2010 (Proceedings of the 27th Annual Conference of the Mathematics Education Research Group of Australasia ( $p p$. 430-437). Sydney, Australia: MERGA.

Resnick, L. B., Nesher, P., Leonard, F., Magone, M., Omanson, S., \& Peled, I. (1989). Conceptual bases of arithmetic errors: The case of decimal fractions. Journal for Research in Mathematics Education, 20, 8-27. https://doi.org/10.2307/ 749095

Rinne, L. F., Ye, A., \& Jordan, N. C. (2017). Development of fraction comparison strategies: A latent transition analysis. Developmental Psychology, 53(4), 713-730. https://doi.org/10.1037/ dev0000275

Smith, C. L., Solomon, G. E., \& Carey, S. (2005). Never getting to zero: Elementary school students' understanding of the infinite divisibility of number and matter. Cognitive Psychology, 51(2), 101-140. https://doi.org/10.1016/j.cogpsych. 2005.03.001

Stafylidou, S., \& Vosniadou, S. (2004). The development of students' understanding of the numerical value of fractions. Learning and Instruction, 14(5), 503-518. https://doi.org/10.1016/j.learninstruc. 2004.06.015

Streefland, L. (1991). Fractions in realistic mathematics education: A paradigm of developmental research. Dordrecht, The Netherlands: Kluwer

Vamvakoussi, X., \& Vosniadou, S. (2004). Understanding the structure of the set of rational numbers: A conceptual change approach. Learning 
and Instruction, 14(5), 453-467. https://doi.org/ 10.1016/j.learninstruc.2004.06.013

Vamvakoussi, X., Van Dooren, W., \& Verschaffel, L (2012). Naturally biased? In search for reaction time evidence for a natural number bias in adults. The Journal of Mathematical Behavior, 31(3), 344-355. https://doi.org/10.1016/ j.jmathb.2012.02.001

Van Dooren, W., Lehtinen, E., \& Verschaffel, L. (2015). Unraveling the gap between natural and rational numbers. Learning and Instruction, 37, 14. https://doi.org/10.1016/j.learninstruc. 2015 . 01.001

Van Hoof, J., Degrande, T., Ceulemans, E. Verschaffel, L., \& Van Dooren, W. (2018). Towards a mathematically more correct understanding of rational numbers: A longitudinal study with upper elementary school learners. Learning and Individual Differences, 61, 99-108. https://doi.org/ 10.1016/j.lindif.2017.11.010

Van Hoof, J., Degrande, T., McMullen, J., HannulaSormunen, M., Lehtinen, E., Verschaffel, L., \& Van Dooren, W. (2016). The relation between learners' spontaneous focusing on quantitative relations and their rational number knowledge. Studia Psychologica, 58(2), 156-170. https://doi.org/ 10.21909/sp.2016.02.714

Van Hoof, J., Lijnen, T., Verschaffel, L., \& Van Dooren W. (2013). Are secondary school students still hampered by the natural number bias? A reaction time study on fraction comparison tasks. Research in Mathematics Education, 12(2), 154-164. https:/ /doi.org/10.1080/14794802.2013.797747 